\title{
KNOWLEDGE, ATTITUDE, AND PRACTICES OF SELF-MEDICATION AMONG THE STUDENTS OF PRIVATE UNIVERSITY
}

\author{
JALPA SUTHAR, PATEL SHRINA P, SOLANKI RIDDHI N
}

Department of Pharmacology, Ramanbhai Patel College of Pharmacy, Charotar University of Science and Technology, Changa, Gujarat, India. Email: jalpasuthar.ph@charusat.ac.in

Received: 20 April 2020, Revised and Accepted: 26 May 2020

\section{ABSTRACT}

Objectives: Self-medication is becoming very common in our routine life which is an unhealthy and risky practice in a few instances. The present study was carried out to determine the knowledge, attitude, and practice of self-medication among students of Charotar University of Science and Technology (CHARUSAT).

Methods: A pre-validated questionnaire was prepared and distributed among the students. Data was collected and analyzed using Microsoft Excel and the results expressed as counts and percentages.

Results: A total of 431 students participated voluntarily in the study. The most common reason for taking self-medication was found in $70 \%$ of total students. We found that the source of information of the drugs used for self-medication was "previous prescription (57\%)" and source of drugs was "medical store (66\%)." Only (46\%) students accepted the fact that they always visited a qualified practitioner whenever they felt ill. Most of the students took self-medication for headache (82\%) followed by cough, cold, and sore throat (62\%) and fever (57\%). Of total 431 students, most of the students took analgesics (78\%) as self-medication followed by lozenges (50\%).

Conclusion: Self-medication was common in nearly $70 \%$ of university students. They provided the reason that "no needs to visit the doctor for minor illness." Cough and cold preparations were taken by $82 \%$ population as self-medication.

Keywords: Self-medication, Questionnaire, Knowledge, Attitude, Practice.

(C) 2020 The Authors. Published by Innovare Academic Sciences Pvt Ltd. This is an open access article under the CC BY license (http://creativecommons. org/licenses/by/4. 0/) DOI: http://dx.doi.org/10.22159/ajpcr.2020.v13i8.37989

\section{INTRODUCTION}

Self-medication is a common and regular practice of using medicines, common over-the-counter (OTC) drugs without any medical supervision, by the people themselves for self-treatment, considering it a part of selfcare in both developed and developing countries [1,2]. Self-medication is reported to be higher in developing countries, mostly due to the fact that people generally consider it as first aid in treating minor ailments or acute symptoms such as vomiting, headache, nausea, fever, and cold [3]. However, few other reasons reported that could lead to self-medication includes previous experience of treating similar diseases, knowledge of drugs and their use, incessant advertising, and lack of availability of qualified health professionals [1]. There are many factors that influence the practice of self-medication among students such as easy availability of drugs, advertising of drug manufacturers, and previous experiences with symptoms or disease [4,5]. If self-medication is used properly, it saves time and money spent. Irrational use of self-medication may increase the risk of adverse events, bacterial infection, hypersensitivity, drug resistance, drug withdrawal symptom, and of masking disease which can delay correct diagnosis [6]. Responsible self-medication plays a key role in the appropriate use of non-prescription drugs which will improve safety and reduces unwanted effects of drugs [7]. The source of self-medication is usually families, friends, pharmacist, previous prescribed drugs, books, drug advertisement, and internet [8].

Students with medical and non-medical background during their undergraduate years of study are not legally eligible to prescribe medicines despite their increasing knowledge about the drug and diseases. Thus, they may be in a unique situation with regard to selfmedication. Recent studies have shown self-medication to be common among medical students and the incidence was high in medical colleges of South India (92\%) [9], Karachi (76\%) [10], and Egypt (55\%) [11].
Self-medication among medical students may be more because they are empowered with a good educational level, greater access to medicine and information, and knowledge of diseases [12].

There is a paucity of studies on self-medication among the blend of all disciplined students in Gujarat. Hence, with this background, the present study was aim to determine the extent and pattern of selfmedication among the students of CHARUSAT campus and to assess practice, attitude, and knowledge of the self-medication in campus.

\section{METHODS}

Study site

A study was conducted among the students of CHARUSAT Campus, Changa.

\section{Study design}

A cross-sectional study based on the questionnaire of self-medication was prepared with the help of standard reference [3,7] and it was developed in the English language for data collection.

\section{Data collection process}

A questionnaire-based survey was carried out by a group of students. A brief description of the nature of the study and the background of the questionnaire was explained to students taking part in the study. All students gave informed consent to participate in the study. The information on the questionnaire on self-medication practices provided to all participants. The leading question included a habit of selfmedication practice (yes or no) and subsequent questions on age, sex, education status, source of information, knowledge about appropriate self-medication practice, types of drugs used for self-medication, and diseases that lead to self-medication were included in the study. 


\section{Data analysis}

Data were presented as number counts and percentages. A descriptive analysis was used to represent the data. Microsoft Excel was used for the analysis of data.

\section{RESULTS}

A total of 431 students participated, of them 148 (34\%) were males and 283 (66\%) were females (Fig. 1). The mean age was $20.5 \pm 2$ years, with a range from 18 to 23 years.

Of 431 students, total 291 (68\%) students took self-medication and the rest 140 (32\%) students have not taken self-medication ever till now (Fig. 2).

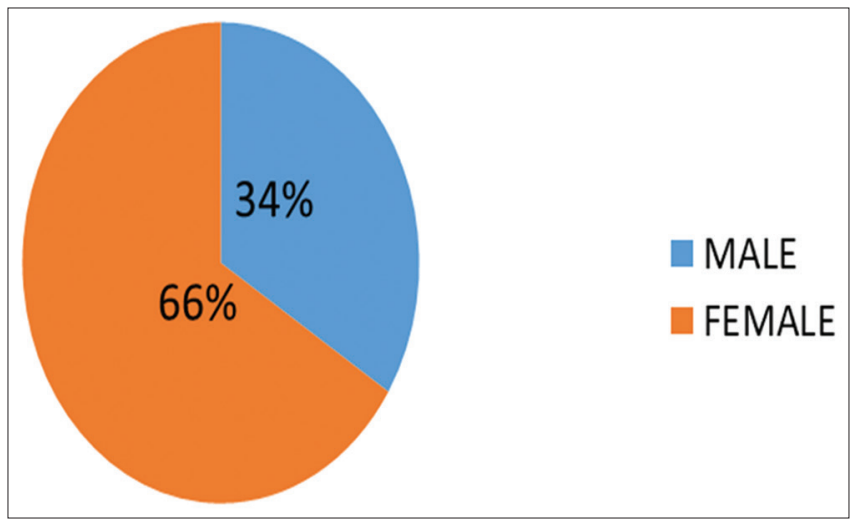

Fig. 1: Distribution of students based on gender $(n=431)$

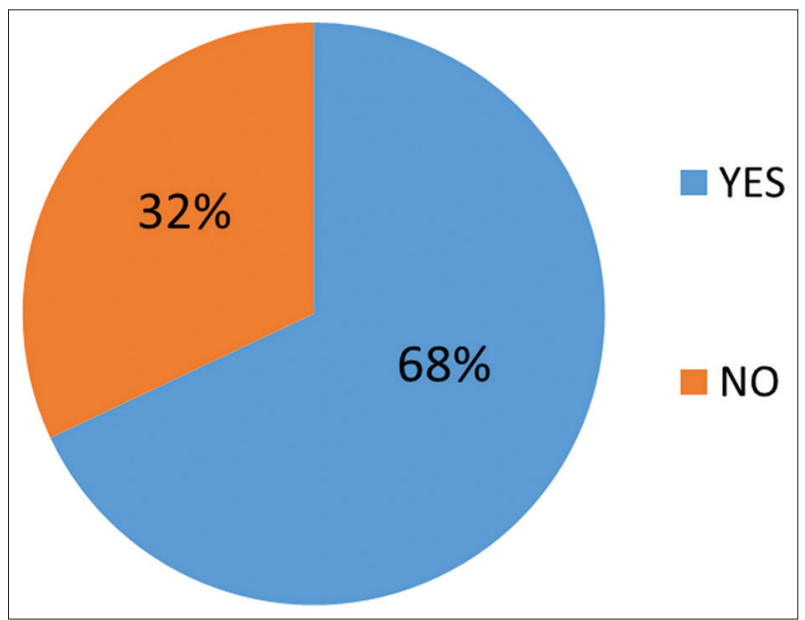

Fig. 2: Distribution of students resorting to self-medication $(n=431)$

\section{Knowledge}

Most common reasons for taking self-medication were that "there was no need to visit doctor for minor illness 197 (70\%)" followed by "selfmedication provided quick relief 134 (46\%)," "it was time-saving 109 (37\%)," and "there were ease and convenience in taking self-medication 91 (31\%)" (Fig. 3).

The source of the drugs used for self-medication was "medical store 193 $(66 \%)$ ". Furthermore, the source of information of the drugs used for self-medication was "previous prescription 167 (57\%)" (Figs. 4 and 5).

The most common reason for not taking self-medication were such as "there was lack of knowledge about medicines 86 (61\%)," "risk of adverse effects 71 (51\%)," "risk of using wrong drugs 64 (46\%)," and "risk of misdiagnosing 45 (32\%)" (Fig. 6).

\section{Attitude}

In our study, we found that of 431 students only 133 (46\%) students accepted the fact that "they sometimes visited a qualified medical practitioner whenever they felt ill," while 93 (32\%) students said that "they always visited" and 89 (31\%) students "visited rarely" (Fig. 7).

\section{Practice}

Of 431 students, most of the students 239 (82\%) took self-medication for headache followed by cough, cold, and sore throat 180 (62\%) and fever 166 (57\%). Of 431 students, most of the students 228 (78\%) took analgesics as self-medication followed by cough and cold preparation 144 (50\%) (Figs. 8 and 9).

\section{DISCUSSION}

Students in CHARUSAT University are doing self-medication very often. In the present study, 431 students of the university were contacted and from that $68 \%$ students answered "YES" in reference to self-medication. It indicates that the overall incidence of self-medication is high in our university, which is similar to previous studies [13-15].

In our study, female students (66\%) were interested in taking selfmedication most often as compare to male students (34\%). The reason for the higher use of self-medication in female students is ignorance to visit hospitals for minor illness. A similar study was done which found parallel observations [16].

\section{Knowledge}

In the current study, most of the students used self-medication in favor that "there was no need to visit the doctor for minor illness 197 (70\%)," "self-medication provided quick relief 134 (46\%)," "it was time-saving 109 (37\%)," and "there were ease and convenience in taking self-medication 91 (31\%)." This is because of rest of the students are not taking self-medication due to "there was a lack of knowledge about medicines 86 (61\%)," "risk of adverse effect

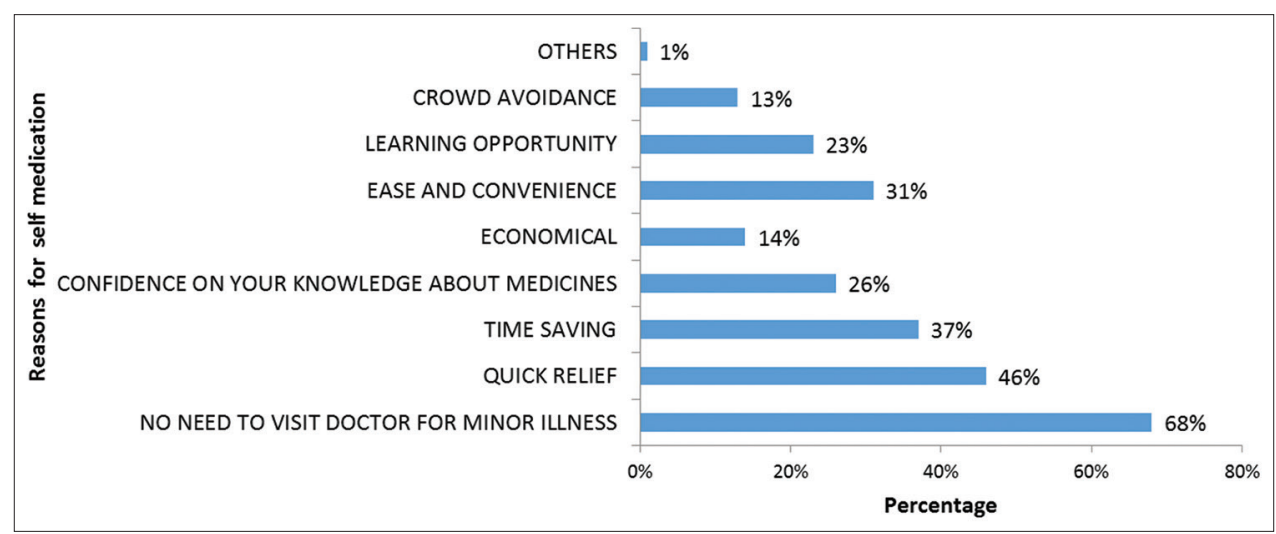

Fig. 3: Reasons for self-medication 


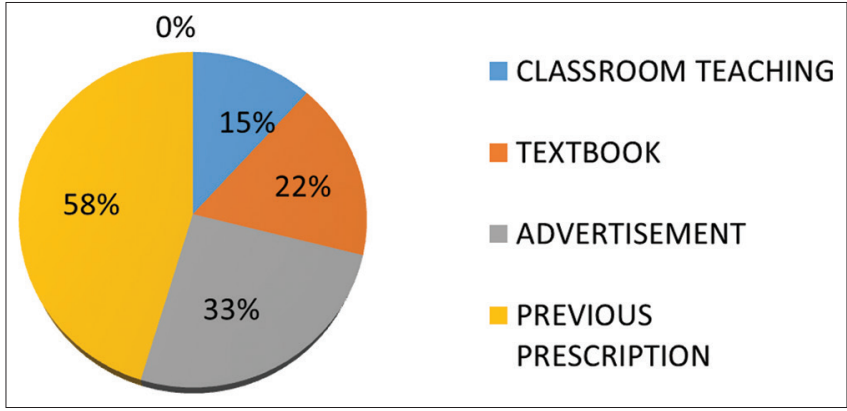

Fig. 4: Sources of drug information for self-medication

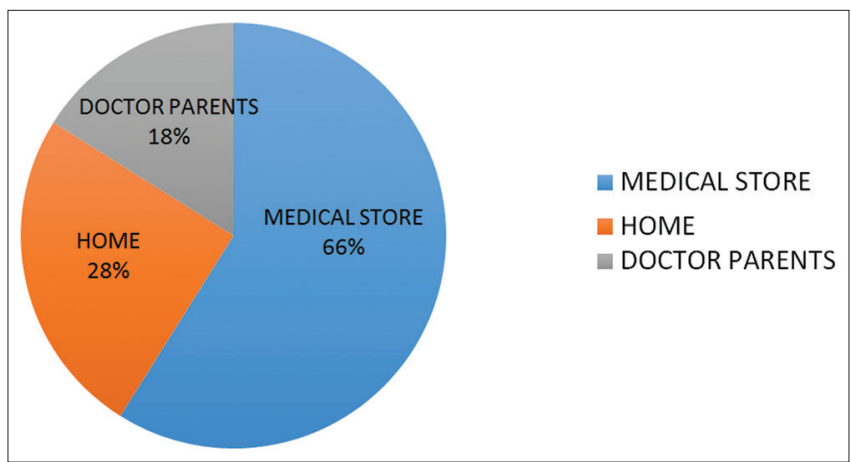

Fig. 5: Sources of drug for self-medication

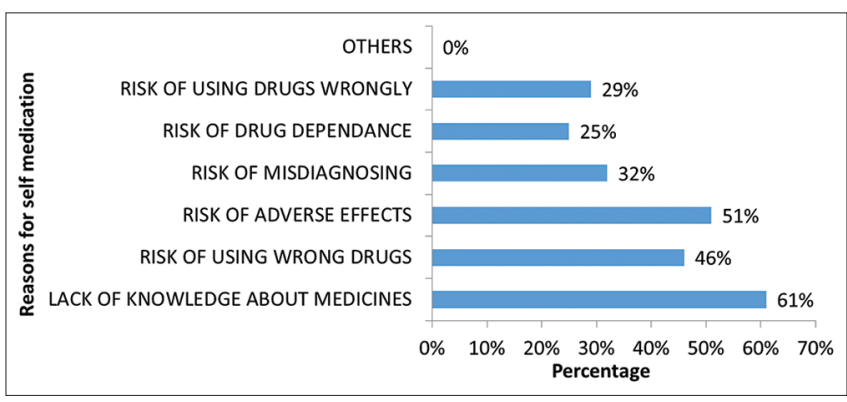

Fig. 6: Reasons for not taking self-medication

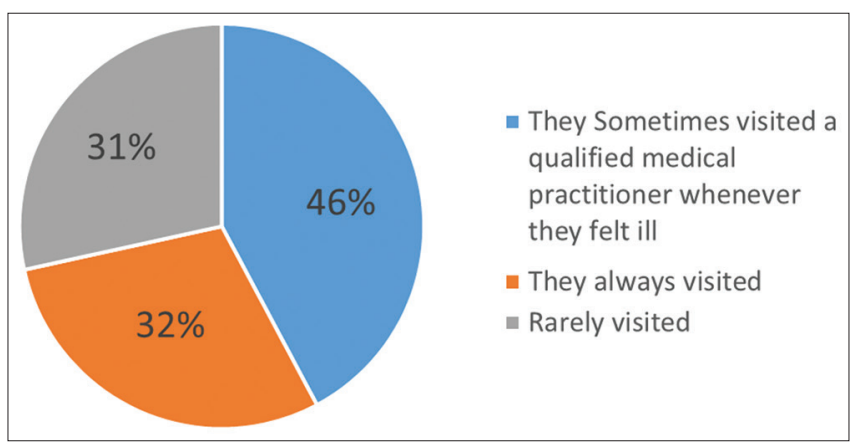

Fig. 7: Attitude of students while visiting hospital

71 (51\%)," "risk of using wrong drugs 64 (46\%)," and "risk of misdiagnosis 45 (32\%)." Similar findings were observed by previous studies $[17,18]$

In the present study, the majority of the students used "previous prescription" as a source of information about drugs. However, other sources such as advertisements, textbooks, and classroom teaching also influence self-medication knowledge in the study. The finding clearly indicates that students of the university avoid to visit the doctor

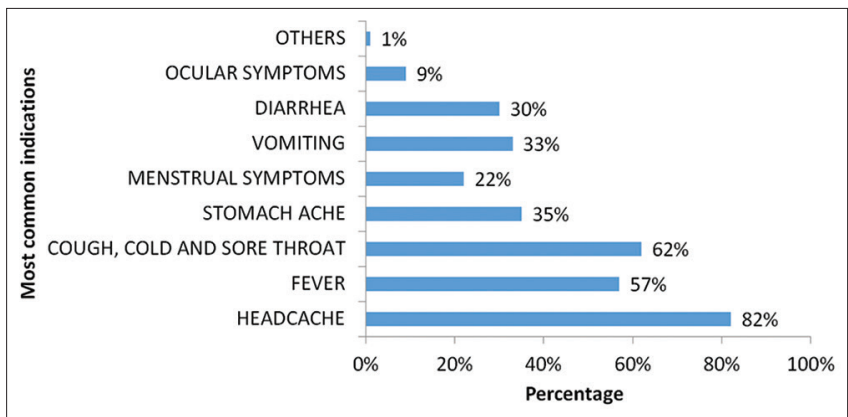

Fig. 8: Indication for the use of self-medication

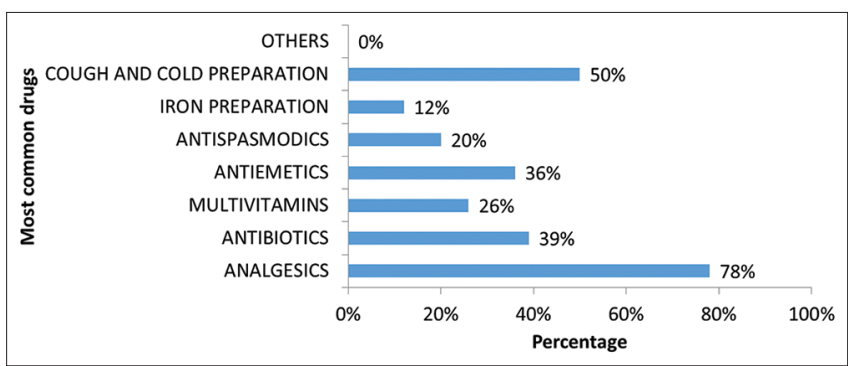

Fig. 9: Drugs used for self-medication

again for the same type of complaint and use the previous prescription as a source of information. The World Health Organization has also pointed out that responsible self-medication can help prevent and treat ailments that do not require medical consultation and provide a cheaper alternative for treating common diseases [19]. However, it is also recognized that self-medication must be accompanied by appropriate health information.

The study highlights different sources of information about drugs used for self-medication such as medical store, home, and doctor parents. We found the majority of the students refer "medical store 193 (66\%)" for self-medication. While sources such as home and doctor parents for self medication have contributed less in present study. In India, the majority of the population consults community pharmacists for their minor illnesses and avoid visiting doctors for minor illnesses. Hence, a similar finding was seen in a few prior studies $[13,20]$. The study conducted in Manipal University, Mangalore was reported that the most common reason for self-medication reported by a large number of participants was the illness being too trivial and lack of time to consult a doctor [21].

\section{Attitude}

The attitude of CHARUSAT University students toward hospital visits was found (32\%) always, (31\%) rarely, and (46\%) visited a medical practitioner sometimes. It concluded that attitude toward self-medication is causal in nature with indicated only $32 \%$ participants visited the hospital for their medical conditions. Similar findings reported by Ali et al. [22].

\section{Practice}

In the present study, the majority of the students did self-medication for the indication of "headache (82\%)" followed by "cough, cold, and sore throat (62\%)" and "fever (57\%)." The self-medication may find rational when the situation is not serious and the complaint is well evident $[14,23]$ such as headache, cough, cold, and sore throat. The use of OTC medicine may be justified only if the safety is high and drug-related side effects are less. Similar findings on practice and indication for self-medication are seen in earlier studies [14,16,17]. Analgesics have been reported to be the most commonly used group of drugs $[24,25]$. Likewise, in our study, we also found similar results. The use of antibiotics is $40 \%$ in the present study. The finding is opposite to the previous studies $[17,26]$. 


\section{CONCLUSION}

Self-medication was common in nearly $70 \%$ of our university students. They provided the reason that "no needs to visit the doctor for minor illness." Cough and cold preparations were taken by $82 \%$ population as self-medication. Many diseases have similar symptoms, and a person using previous experience may be exposed to the dangers of misdiagnosis and consequently wrong treatment. However, self-medication is advantages in certain cases and benefiting consumers. Even though monitoring of sale of drugs with sideeffects must be implemented and restrictions should be put among stakeholders and pharmacists.

\section{AUTHORS' CONTRIBUTIONS}

Jalpa Suthar: Concept, statistical analysis, manuscript final preparation, manuscript editing, and manuscript review. Remaining authors: Manuscript drafting, literature search, data acquisition, and data analysis.

\section{CONFLICTS OF INTEREST}

The authors declare that they have no conflicts of interest.

\section{AUTHORS' FUNDING}

Nil.

\section{REFERENCES}

1. Musa Y, Awosan KJ, Ibrahim MT, Abdullahi Z, Jafaar MM, Peter G, et al. Knowledge and practice of self-medication among undergraduate students of Usmanu Danfodiyo University, Sokoto. Ann Int Med Dent Res 2016;2:83

2. Khamis S, Sheqer H, Arsoy G. Knowledge, attitude and practice of selfmedication among pharmacy students in North Cyprus. Int J Pharm Sci Res 2019;29:1-10.

3. Gyawali S, Shankar PR, Poudel PP, Saha A. Knowledge, attitude and practice of self-medication among basic science undergraduate medical students in a medical school in western Nepal. J Clin Diagn Res 2015;9:FC17.

4. Bhatia MK, Ripudaman S, Akashdeep S, Bhardwaj BL. Knowledge, attitude and practice of self-medication among undergraduate medical students of Punjab. Glob J Med Res 2017;3:151-4.

5. World Health Organization. Report of the WHO Expert Committee on National Drug Policies. Geneva: World Health Organization; 1995. https://www.who.int/medicines/library/dap/who-dap-95-9/whp-dap95.9.shtml.

6. Jain S, Malvi R, Purviya JK. Concept of self-medication: A review. Int J Pharm Biol Arch 2011;2:831-6.

7. Sankdia RK, Agrawal M, Rekha PB, Kothari N. A questionnaire-based study regarding the knowledge, attitude and practice of self-medication among second year undergraduate medical students. Int J Pharmacol 2017;6:1-5.

8. Faiz A, Seema M, Deep I, Shaista A. Self-medication practices and attitude among dental students of a metro city of North India. Int $\mathbf{J}$ Biomed Res 2018;4:118-21.

9. Badiger S, Kundapur R, Jain A, Kumar A, Pattanshetty S, Thakolkaran N, et al. Self-medication patterns among medical students in South India. Med J Aust 2012;5:217-20.

10. Zafar SN, Syed R, Waqar S, Irani FA, Saleem S. Prescription of medicines by medical students of Karachi, Pakistan: A cross-sectional study. BMC Public Health 2008;8:162.

11. El Ezz NF, Ez-Elarab HS. Knowledge, attitude and practice of medical students towards self-medication at Ain Shams University, Egypt. Int J Prev Med 2011;52:196-200.

12. Mehta RK, Sharma S. Knowledge, attitude and practice of self-medication among medical students. IOSR Nurs Health Sci 2015;4:89-96.

13. Klemenc-Ketis Z, Hladnik Z, Kersnik J. Self-medication among healthcare and non-healthcare students at University of Ljubljana, Slovenia. Med Prin Pract 2010;19:395-401.

14. Mumtaz Y, Jahangeer SA, Mujtaba T, Zafar S, Adnan S. Self-medication among university students of Karachi. J Liaquat Univ Med Health Sci 2011; 10:102-5.

15. Raut P, Vamsi D, Rao BV. Evaluation of the knowledge, attitude and practice of self-medication among second year B.Sc nursing students. J Drug Deliv Sci Technol 2014;4:150-3.

16. Thadani S, Salman MT, Ahmad A. Knowledge, Attitude and practice of self-medication among second year undergraduate medical students. J Ration Pharmacother Res 2013;1:131-4.

17. James H, Handu SS, Al Khaja KA, Otoom S, Sequeira RP. Evaluation of the knowledge, attitude and practice of self-medication among firstyear medical students. Med Princ Pract 2006;15:270-5.

18. Montgomery AJ, Bradley C, Rochfort A, Panagopoulou E. A review of self-medication in physicians and medical students. Occup Med 2011;61:490-7.

19. Kafle KK, Gartoulla RP. Self-medication and its Impact on Essential Drugs Schemes in Nepal: A Socio-cultural Research Project. In: DAP Research Series. Geneva: World Health Organization; 1993.

20. Kulkarni P, Ajmera A, Gadekar S, Garg A, Mahajan A, Kulkarni P. Global scenario of self-medication: A review of literature. Indian J Commer Manag Stud 2018;9:99-107.

21. Johnson D, Sekhar HS, Alex T, Kumaraswamy M, Chopra RS. Self medication practice among medical, pharmacy and nursing students. Int J Pharm Pharm Sci 2017;8:443-7.

22. Ali SE, Ibrahim MIM, Palaian S. Medication storage and selfmedication behavior amongst female students in Malaysia. Pharm Pract 2010;8:226-32.

23. Susheela F, Goruntla N, Bhupalam PK, Veerabhadrappa KV, Sahithi B, Ishrar SM. Assessment of knowledge, attitude, and practice toward responsible self-medication among students of pharmacy colleges located in Anantapur district, Andhra Pradesh, India. Int J Health Promot Educ 2018;7:96.

24. Hughes CM, mcelnay JC, Fleming GF. Benefits and risks of selfmedication. Drug Saf 2001;24:1027-37.

25. Aljinović-Vučić V, Trkulja V, Lacković Z. Content of home pharmacies and self-medication practices in households of pharmacy and medical students in Zagreb, Croatia. Croat Med J 2005;46:74-80.

26. Hailemichael W, Sisay M, Mengistu G. Assessment of knowledge, attitude, and practice of self-medication among Harar health sciences college students, Harar, Eastern Ethiopia. J Drug Deliv Ther 2016;6:31-6. 